http://jmscr.igmpublication.org/home/

ISSN (e)-2347-176x ISSN (p) 2455-0450

crossref DOI: https://dx.doi.org/10.18535/jmscr/v9i11.36

Journal Of Medical Science And Clinical Research

\title{
A Study on Treatment of Tennis Elbow by Platelet Rich Plasma
}

\author{
Authors \\ Dr Rahmat Ali (Ms (Ortho), MCh (Ortho)) Fellowship Spine ${ }^{1}$, Dr Zafar Anis ${ }^{2}$ \\ ${ }^{1}$ Professor and H.O.D (Ortho department), Maharishi Vashishtha Autonomous State Medical College, Basti, \\ UP, India \\ ${ }^{2}$ M.O. District Hospital, Deoria, UP, India
}

\begin{abstract}
Background: In routine practice tennis elbow or lateral epicondylitis is commonly encountered enthesopathy, which disturbs the activity of daily life and it not only effects sports personnel but in our society major chunk of patients affected by it are house wife's and manual workers, so an effective low-cost treatment modality is need of the hour. Autologous platelet-rich plasma (PRP) hastens the healing of angiofibroblastic degeneration in lateral epicondylitis by providing humoral modulators and array of different growth factors favours its use to treat enthesopathies.

Keywords: Lateral epicondylitis, Elbow, Platelet rich plasma (PRP).
\end{abstract}

\section{Introduction}

Pain and tenderness around lateral epicondyle of the elbow* is a common complaint among tennis players but even more common in non-players who perform similar activities involving forceful repetitive wrist extension. It is extensor carpi radialis brevis and longus tendons(which automatically extends the wrist when gripping) which become pathological in tennis elbow. It may result in small tears and fibrocartilaginous metaplasia. Tendon repair is usually slow due to low vascular supply. Platelet rich plasma has emerged as a latest modality of treatment in refractory tennis elbow. Various modalities have been used in treatment of refractory Tennis elbow like local steroid, Dry needling and surgical intervention

is needed in the treatment of chronic tennis elbow. Platelets are integral component of the healing process, acting as a reservoir for growth factors involved in the repair process. Following injury, the endogenous inflammatory response leads to platelets being activated and delivering an array of growth factors to the site of injury, including platelet-derived growth factor (PDGF), transforming growth factor-beta (TGF- $\beta$, epidermal growth factor (EGF).

Platelet-rich plasma (PRP) has 2-to-5fold increase in platelet concentration and 1-to-15fold growth factor concentrations of that of blood. The proposed proliferative and angiogenic effect of PRP makes it feasible treatment the typical poor vascularity and extracellular matrix injury breakdown involved in common extensor tendon injury.

\section{Materials and Methods}

This short-term longitudinal study includes management of lateral epicondylitis by autologous PRP infiltration. All the patients were consulted 
and thoroughly examine at outpatient department and those fulfilling the inclusion and exclusion criteria were subjected to local infiltration of PRP and evaluated according to Verhaar et al score, at a teaching Hospital from East UP between April2019 to July-2021.

\section{Inclusion Criteria}

1. Age 20-55 years.

2. Pain severity with minimum score of 5 (based on 10 scale) Visual Analogue Score (VAS)

3. Painful unilateral or bilateral involvement of lateral epicondyle.

4. Duration of symptom for more than 6 months.

5. Tennis elbow to conservative management. That is which did not responded to conservative treatment for at least 2 months.

\section{Exclusion Criteria}

1. Radial Funnel syndrome.

2. Pregnancy, bony or articular lesions at elbow.

3. Any local skin pathology at injection site.

4. A history of patient obtaining cortisone.

5. Patient already undergone surgical intervention.

6. Systemic disease like diabetes, rheumatoid arthritis in patients.

7. Use of NSAID's within a week before procedure.

8. Six patients were included in our study out of which 4 were females and 2 were males.

\section{Technique of PRP}

The procedure consists of $40 \mathrm{ml}$ venous blood sample drawn under aseptic conditions in a $50 \mathrm{ml}$ dispovan syringe with $4 \mathrm{ml}$ CPD-AI or $4 \mathrm{ml} 3.2 \%$ sodium citrate as anticoagulant. The unit of PRP was divided into 2 small units for $1 \mathrm{ml}$ and $3 \mathrm{ml}$. One $\mathrm{ml}$ was sent to the laboratory for analysis of platelet concentration and microbiological assessment. This could be considered as an advantage since it increases the safety of procedure, thus ensuring a controlled not contaminated intra articular delivery of product whereas remaining was stored at $10-20^{\circ} \mathrm{C}$. After getting quality analysis (platelet concentration in PRP should be 3-5 times to platelet count in the blood of patient) of PRP (preferably within 2 hours). Patients were laid supine with elbow semiflexed lateral epicondyle palpated adjoining most tender area is pointed out then under aseptic condition. 3ml of PRP was injected in to under surface of the extensor carpi radialis brevis and adjoining area of lateral epicondyle. Single injection of PRP was given with no external platelet activator. After infiltration of PRP patients were advised supervised physiotherapy and advised cold compression and given Analgesic for pain relief. Patients were advised to abstain from regular activities for 3 weeks. The patients were evaluated according to Verhaar et.al scoring system.

\section{Verhaar et. al scoring system}

\section{Excellent}

1. Complete relief of pain on the lateral epicondyle.

2. Patient satisfied with the result of treatment.

3. No subjective loss of grip strength.

4. No pain provoked by resisted dorsiflexion of the wrist.

\section{Good}

1. Occasional slight pain on the lateral epicondyle after strenuous activities.

2. Patient satisfied with the result of treatment.

3. No or slight subjective loss of grip strength.

4. No pain provoked by resisted dorsiflexion of the wrist.

\section{Fair}

1. Discomfort on the lateral epicondyle after strenuous activities but at a more tolerable level than before treatment.

2. Patient satisfied on moderately satisfied with the result of treatment.

3. Slight or moderate subjective loss of grip strength.

4. Slight or moderate pain provoked by resisted dorsiflexion of the wrist.

\section{Results}

The data assimilated on (Pre-Infiltration) day one, 
$8^{\text {th }}$ week and $12^{\text {th }}$ week was analysed. Significant improvement was seen at 8 weeks and 12 weeks follow-up. There was excellent to good improvement in $60 \%$ of patients at 8 weeks while $40 \%$ of the patients showed significant improvement at 12 weeks of follow-up.

\section{Discussion}

A lateral epicondylitis is a well-known problem disturbing day to day activity of professionally active individuals of all the ages. Varying therapeutic options include extracorporeal shock wave therapy, Local Steroidal injection, Autologous whole blood, Dry needling and surgical intervention suggesting that no single procedure is effective in all patients. Majority of the patients respond to non-surgical treatment, a small minority continues to persist with these symptoms and is labelled as resistant tennis elbow. Khaliq et al, in a study of corticosteroid versus PRP in lateral epicondylitis found PRP to be more effective than corticosteroid in reduction of pain and improvement of function. Our study also offers encouraging results of an alternative minimally invasive treatment that addresses the pathophysiology of lateral epicondylitis over other traditional non-surgical modalities. Patients showed functional outcome with excellent to good result as per Verhaar et al score.

\section{Conclusion}

Our study showed preliminary results with Platelet Rich Plasma infiltration and it is safe and effective modality for treatment of these cases. It is also cost effective.

\section{Reference-}

1. Ellenbecker TS, Nirschl R, Renstrom P. Current concepts in examination and treatment of elbow tendon injury. Sports Health 2013;5:186- 94.

2. Solomon L, Warwick D, Nayagam S. Tennis Elbow (Lateral Epicondylitis) in Regional Orthopaedics, Apley's System of Orthopaedics and Fractures. 9th ed.
London: Published by CRC Press; 2010. p. 378-9.

3. De Smedt T, de Jong A, Van Leemput W, Lieven D, Van Glabbeek F. Lateral epicondylitis in tennis: Update on aetiology, biomechanics and treatment. $\mathrm{Br}$ J Sports Med 2007;41:816-9.

4. De La Mata J. Platelet rich plasma. A new treatment tool for the rheumatologist? Reumatol Clin 2013;9:166-71.

5. Hall MP, Band PA, Meislin RJ, Jazrawi LM, Cardone DA. Platelet-rich plasma: Current concepts and application in sports medicine. J Am Acad Orthop Surg 2009; 17:602-8.

6. de Mos M, van der Windt AE, Jahr H, van Schie HT, Weinans H, Verhaar JA, et al. Can platelet-rich plasma enhance tendon repair? A cell culture study. Am J Sports Med 2008;36:1171-8.

7. Anitua E, Andía I, Sanchez M, Azofra J, del Mar Zalduendo M, de la Fuente M, et al. Autologous preparations rich in growth factors promote proliferation and induce VEGF and HGF production by human tendon cells in culture. J Orthop Res 2005;23:281-6.

8. Kahlenberg CA, Knesek M, Terry MA. New developments in the use of biologics and other modalities in the management of lateral epicondylitis. Biomed Res Int 2015;2015:439309.

9. Raeissadat SA, Sedighipour L, Rayegani SM, Bahrami MH, Bayat M, Rahimi R. Effect of platelet-rich plasma (PRP) versus autologous whole blood on pain and function improvement in tennis elbow: a randomized clinical trial. Pain Res Treat 2014;2014:191525.

10. Verhaar JA, Walenkamp GH, van Mameren $\mathrm{H}$, Kester AD, van der Linden AJ. Local corticosteroid injection versus cyriax-type physiotherapy for tennis elbow. J Bone Joint Surg Br 1996;78:12832. 
11. Perez AG, Lana JF, Rodrigues AA, Luza AC, Belanera WD, Helena AM, et al. Relevant aspects of centrifugation step in the preparation of Platelet rich plasma. ISRN Hematol 2014;8:17060.

12. Greene WB, editor. Essentials of Musculoskeletal Care. 2nd ed. Rosemont, IL: Published by the American Academy of Orthopaedic Surgeons; 2001.

13. Haake M, König IR, Decker T, Riedel C, Buch M, Müller HH, et al. Extracorporeal shock wave therapy in the treatment of lateral Epicondylitis: A randomized multicenter trial. J Bone Joint Surg Am 2002;84-A:1982-91.

14. Chesterton LS, Mallen CD, Hay EM. Management of tennis elbow. Open Access J Sports Med 2011;2:53-9.

15. Yadav R, Kothari SY, Borah D. Comparison of local injection of platelet rich plasma and corticosteroids in the treatment of lateral epicondylitis of Humerus. J Clin Diagn Res 2015;9:RC057. 